\title{
Persistent transcriptional responses show the involvement of feed-forward control in a repeated dose toxicity study
}

Citation for published version (APA):

de Souza, T., Rieswijk, L., van den Beucken, T., Kleinjans, J., \& Jennen, D. (2017). Persistent transcriptional responses show the involvement of feed-forward control in a repeated dose toxicity study. Toxicology, 375, 58-63. https://doi.org/10.1016/j.tox.2016.10.009

Document status and date:

Published: 15/01/2017

DOI:

10.1016/j.tox.2016.10.009

Document Version:

Publisher's PDF, also known as Version of record

Document license:

Taverne

Please check the document version of this publication:

- A submitted manuscript is the version of the article upon submission and before peer-review. There can be important differences between the submitted version and the official published version of record.

People interested in the research are advised to contact the author for the final version of the publication, or visit the DOI to the publisher's website.

- The final author version and the galley proof are versions of the publication after peer review.

- The final published version features the final layout of the paper including the volume, issue and page numbers.

Link to publication

\footnotetext{
General rights rights.

- You may freely distribute the URL identifying the publication in the public portal. please follow below link for the End User Agreement:

www.umlib.nl/taverne-license

Take down policy

If you believe that this document breaches copyright please contact us at:

repository@maastrichtuniversity.nl

providing details and we will investigate your claim.
}

Copyright and moral rights for the publications made accessible in the public portal are retained by the authors and/or other copyright owners and it is a condition of accessing publications that users recognise and abide by the legal requirements associated with these

- Users may download and print one copy of any publication from the public portal for the purpose of private study or research.

- You may not further distribute the material or use it for any profit-making activity or commercial gain

If the publication is distributed under the terms of Article $25 \mathrm{fa}$ of the Dutch Copyright Act, indicated by the "Taverne" license above, 


\title{
Persistent transcriptional responses show the involvement of feed-forward control in a repeated dose toxicity study
}

\author{
Terezinha M Souza*, Linda Rieswijk, Twan van den Beucken, Jos Kleinjans, Danyel Jennen \\ Department of Toxicogenomics, Maastricht University, Maastricht, 6229 ER, The Netherlands
}

\section{A R T I C L E I N F O}

\section{Article history:}

Received 9 September 2016

Received in revised form 13 October 2016

Accepted 14 October 2016

Available online 17 October 2016

\section{Keywords:}

Hepatocellular carcinoma

Aflatoxin B1

Feed-forward loop

Network motif

Transcription factor

\section{A B S T R A C T}

Chemical carcinogenesis, albeit complex, often relies on modulation of transcription through activation or repression of key transcription factors. While analyzing extensive networks may hinder the biological interpretation, one may focus on dynamic network motifs, among which persistent feed-forward loops (FFLs) are known to chronically influence transcriptional programming. Here, to investigate the relevance a FFL-oriented approach in depth, we have focused on aflatoxin B1-induced transcriptomic alterations during distinct states of exposure (daily administration during 5 days followed by a non-exposed period) of human hepatocytes, by exploring known interactions in human transcription. Several TF-coding genes were persistently deregulated after washout of AFB1. Oncogene MYC was identified as the prominent regulator and driver of many FFLs, among which a FFL comprising MYC/HIF1A was the most recurrent. The MYC/HIF1A FFL was also identified and validated in an independent set as the master regulator of metabolic alterations linked to initiation and progression of carcinogenesis, i.e. the Warburg effect, possibly as result of persistent intracellular alterations arising from AFB1 exposure (nuclear and mitochondrial DNA damage, oxidative stress, transcriptional activation by secondary messengers). In summary, our analysis shows the involvement of FFLs as modulators of gene expression suggestive of a carcinogenic potential even after termination of exposure.

(C) 2016 Elsevier Ireland Ltd. All rights reserved.

\section{Introduction}

Within toxicology, transcription networks play important roles as target and effectors during xenobiotic exposure. For instance, the aryl hydrocarbon receptor (AhR) is a well-known ligand of many polycyclic aromatic hydrocarbons (PAHs) and a potent inducer of Phase-I metabolizing enzymes (e.g., CYPs). Other examples include networks such as Nrf2/NFE2L2, a vast array of nuclear receptors (NR1-5), tumor suppressor genes (e.g., TP53), hypoxia-inducible factors (HIFs) and oncogenes (MYC) (Jennings et al., 2013). In most cases, distinct levels of induction have been associated with variable risks of toxicity and cancer (Nebert et al., 2004) and understanding the mechanisms of transcriptional activation may improve (early) toxicity prediction and development of biomarkers (Van Summeren et al., 2011).

\footnotetext{
* Corresponding author at: Department of Toxicogenomics, Maastricht University, Universiteitssingel 50, 6200 MD, Maastricht, The Netherlands.

E-mail addresses: t.souza@maastrichtuniversity.nl (T.M. Souza),

linda.rieswijk@maastrichtuniversity.nl (L. Rieswijk),

t.vandenbeucken@maastrichtuniversity.nl (T.v.d. Beucken),

j.kleinjans@maastrichtuniversity.nl (J. Kleinjans),

danyel.jennen@maastrichtuniversity.nl (D. Jennen).
}

Despite that, most investigations of human transcriptional networks are limited to a few TFs at a time due to their complexity: target genes may be redundantly regulated by numerous TFs and interactions are often rewired, yielding different outputs in response to environmental changes or cell state (Blais and Dynlacht, 2005; Vaquerizas et al., 2009). Alternatively, one may focus on network motifs, i.e. smaller and yet autonomous portions of complex networks that retain relevant regulatory aspects. For instance, transcriptional cascades result in sequential gene regulation; feedback loops may generate pulses or oscillations in expression (Alon, 2007). Feedforward loops (FFLs) are particularly interesting since in this case control of a target gene $\mathrm{Z}$ is influenced by the input (activation or repression) of two transcription factors ( $\mathrm{X}$ and $\mathrm{Y}$ ). While $\mathrm{X}$ also targets the expression of $\mathrm{Y}$, both transcription factors are regulated by distinct upstream signals (small molecules, covalent modifications, binding proteins). This creates eight possible configurations (Fig. 1) in which four coherent FFLs show an overall direction of regulation equal to the path established from $\mathrm{X}$ to $\mathrm{Z}$, while four incoherent FFLs present opposite regulation. The coherent-I (C1) is the most common type, anticipating changes in the system and sustaining expression of target genes even under transient deprivation of the activating 

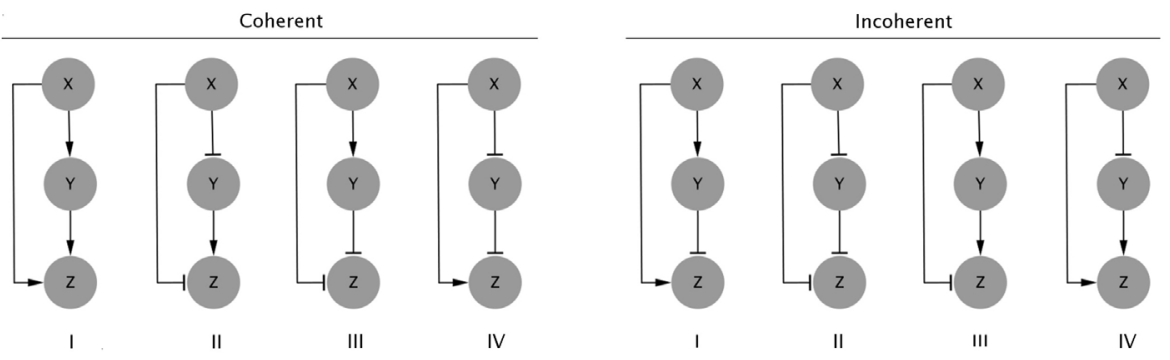

Fig. 1. Overview of all possible configurations of 3-node feed-forward loops (FFLs).

stimulus, whether or not from exogenous origin (Blais and Dynlacht, 2005; Milo et al., 2002). Despite the essential role in maintenance of homeostasis, exacerbated signaling may have undesirable effects, as proposed by an investigation showing a link between activation of a NOTCH1/c-MYC C1 FFL and leukemic cell growth (Palomero et al., 2006).

From a toxicological perspective, network motifs are likely key components of toxic response, and better understanding of their roles may improve outcome of cellular responses and toxicity prediction (Bhattacharya et al., 2011). We hypothesize that toxicants, their intermediate metabolites or intracellular changes arising from exposure may therefore act as upstream signals to activate FFLs, leading to adaptive/adverse responses that may persist even after toxicant removal. To investigate that, we took advantage of our recently published datasets (GSE67005 and GSE71547) (Rieswijk et al., 2016). Both datasets contain transcriptomic measurements from primary human hepatocytes (PHHs), the former after 5 days of repeated dose exposure to a low dose $\left(\mathrm{IC}_{20}\right)$ of aflatoxin B1 (AFB1) and the latter after a 3-day, nonexposed period (washout). AFB1 is a known human carcinogen and an established risk factor for the development of hepatocellular carcinoma (HCC), the main type of primary liver cancer and the third most common cause of cancer-related mortality. Hepatic metabolism of AFB1 generates several metabolites, including $\mathrm{AFB}_{1-}$ 8,9-epoxide which induces DNA lesions by covalently binding to guanine nucleotides (Denissenko et al., 1998). In addition, a recent study in rodents chronically fed with AFB1 (Merrick et al., 2013) showed extensive regulation of several targets from the AhR, Nrf2, E2f1 and other downstream TFs and these alterations may act as key events in the early stages of malignant transformation.

To test our hypothesis, we first constructed a map of human transcription by retrieving curated, directed interactions (activation or repression) between transcription factors and target genes from literature. This map was then used to identify individual transcription factors and/or C1 FFLs and whether they remained active upon removal of the challenging agent AFB1. Finally, the biological relevance and possible impacts were assessed within the scope of (chemical-induced) carcinogenesis.

\section{Methods}

\subsection{Data processing}

Transcriptomic measurements from primary human hepatocytes exposed to AFB1 were obtained from publicly available data deposited on Gene Expression Omnibus (GEO) under the accession numbers GSE67005 (5 days) GSE71547 (washout). Hepatocytes were cultured in a collagen-collagen sandwich layer for $48 \mathrm{~h}$ prior treatment. Following that period, cells were incubated with a relatively low toxic dose of $\mathrm{AFB} 1\left(\mathrm{IC}_{20}, 0.3 \mu \mathrm{M}\right)$, administered daily during 5 days. Thereafter cells were harvested, the RNA isolated and subsequently subjected to microarray analysis. Another batch of hepatocytes that underwent the same treatment was maintained in medium for another 3 days after terminating AFB1 exposure (washout period). RNA was isolated and analyzed as previously. Detailed protocol and procedures are described elsewhere. (Rieswijk et al., 2016)

Raw files from Affymetrix Human Genome U133 Plus 2.0 arrays were assessed for quality control on ArrayAnalysis (arrayanalysis. org) and pre-processed (background correction, probe reannotation and data filtering) using the $\mathrm{R}$ package affy (Gautier et al., 2004). Differentially expressed (DE) genes were selected using moderated $t$-test from LIMMA, a linear model for microarrays. Since experimental data encompassed only mRNA measurements, we worked under the assumption that mRNAs from TFs are expressed at lower levels in comparison to non-TF genes (Vaquerizas et al., 2009) and that expression levels reflect its activity (Blais and Dynlacht, 2005). Therefore, only a corrected $p$-value cutoff (FDR $<0.05)$ was applied to select DE features (target genes and TFs), regardless of fold change thresholds. Identification of TFs was carried out through the Animal transcription factor database (AnimalTFDB, http://www.bioguo. org/AnimalTFDB/), which contains a list of 1544 human regulatory genes including transcription and chromatin remodeling factors, complexes and co-factors.

\subsection{Construction of transcription factor networks}

MetaCore ${ }^{\mathrm{TM}}$ is a tool comprising several methods for analyses of genome-wide data, including pathways, gene ontology and transcription regulation, the latter encompassing a large curated list resulting from diverse experimental approaches. In a comprehensive study, MetaCore has been shown to outperform several databases for retrieving meaningful, validated transcriptional interactions (Shmelkov et al., 2011). Therefore, in order to retrieve regulatory aspects of human transcription, we selected all targets from interactions specified as "activation" or "repression" from each of the 1544 regulatory genes obtained in the previous step. Networks were reconstructed from this human transcription map by selecting the AFB1-induced DEGs for each time point and by adding interactions with all potential TFs that were also identified as differentially expressed.

\subsection{Motif mining}

To identify network motifs, we first visualized the interaction in Cytoscape v. 2.8.3, where a node represented a gene and an edge depicted an interaction connecting two nodes. We used CentiScaPe v. 1.2.1 (Scardoni et al., 2009) to compute (among other centralities) the degree of every node in order to identify top scoring genes, or relevant regulatory hubs, for each condition. Then, another Cytoscape plugin, NetMatch (http://ferrolab.dmi. unict.it/netmatch.html), was used to examine the occurrence of C1 FFLs: the directed pattern of a generic C1 FFL (where TF X activates TF Y and both transcriptionally activate target gene $Z$ ) was matched against the target networks. Among all triads returned by 


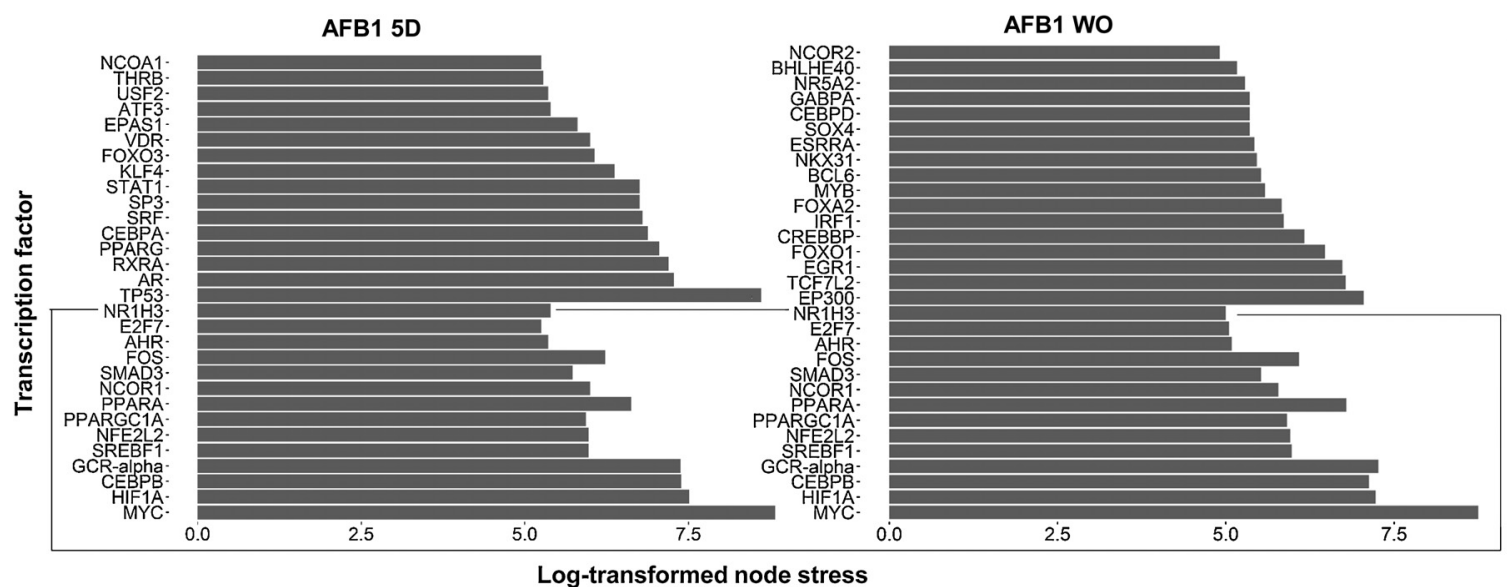

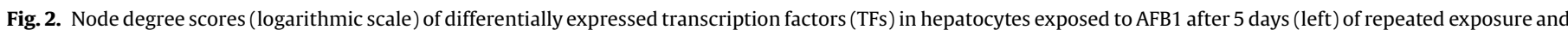

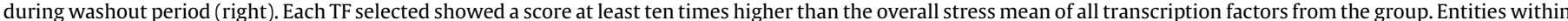
the box indicate common transcription factors regulated in both datasets.

the analysis, we further selected those motifs in which all genes were upregulated, thus representing persistently and consistently activated FFLs.

\section{Results}

\section{1. (Re)Construction of transcription networks}

In order to obtain a snapshot of the human transcription network, data from transcription factors and target genes mined from MetaCore was merged into a single network. This map comprised 41,754 interactions among 1035 TFs/TF complexes and 10,422 distinct target genes, including those coding for TFs resulting in a network too large to display.

AFB1-induced transcription, analysis after the 5-day repeated exposure and 3-day washout period yielded networks with 4380 and 3602 interactions, respectively. Since several genes encoding for TFs were significantly expressed (217 at 5 days and 192 during washout), network centrality analyses allowed the identification of the most important nodes at both time points. For that, the top scoring TFs (log-transformed node degree score higher than the overall group mean) were selected (Fig. 2). After 5 days of repeated exposure to AFB1, we detected TP53, nuclear receptor TFs (AR,PPARA and RXRA), CEBPA, KLF4, STAT1, SP3 and SRF as the most important TFs. Persistent (under)expression was detected during the washout period: MYC, HIF1A, CEBPB, GCRA, PPARGC1A were among TFs persistently upregulated, while SREBF1, PPARA and NR1H3 featured among downregulated TFs.

\subsection{Network motifs in AFB1-induced networks}

In total, we identified 240 unique, putatively activated C1 FFLs during repeated AFB1 exposure. The main regulators included high stress nodes such as MYC, TP53, CEBPB and PPARG; the pairs MYC-TP53, TP53-SMAD3, CEBPB-FOS and MYC-HIF1A regulated $33 \%$ of all gene targets included into FFLs. During washout, 117 C1 FFLs were detected and EP300-MYC appeared as an important regulatory duo. Importantly 25 C1 FFLs were identified in both sets thus representing persistent expression despite the fact that the activating AFB1 impulse was terminated; approximately $60 \%$ of these C1 FFLs resulted from MYC-HIF1A and CEBPB-PPARGC1A joined interactions (Fig. 3).
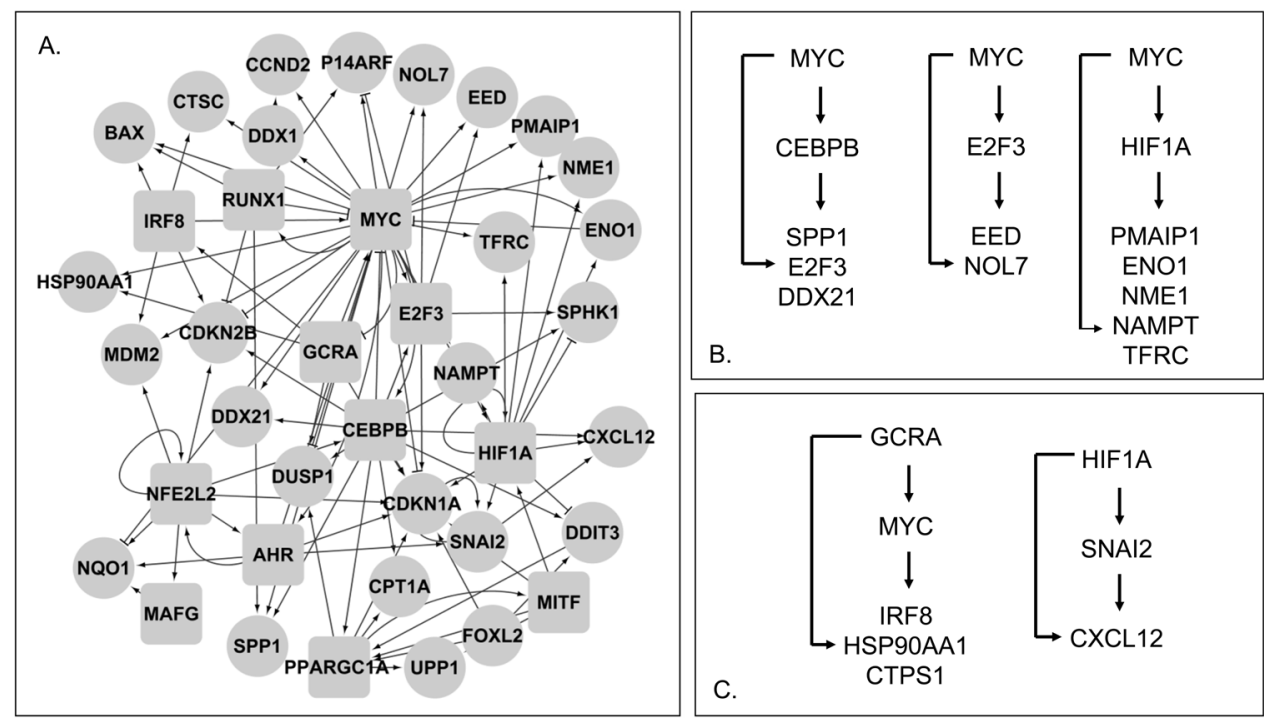

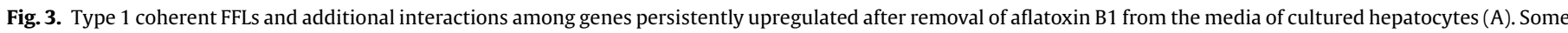
FFLs are detailed in B (all myc-driven) and C (driven by other TFs). 


\section{Discussion}

Transcriptional programming is an ever-changing, crucial determinant of cell fate. Here, we analyzed the effects of a potent hepatocarcinogen, AFB1, on the modulation of transcription networks, with emphasis on C1 FFLs, in human hepatocytes in vitro. The investigation during distinct states of exposure allowed the identification of features persistently expressed after removal of the stressor, some of which appeared embedded in feedforward loops (FFLs).

Repeated challenging with AFB1 over 5 days induced the expression of several TFs, among which TP53 and some of its direct targets involved in cell cycle arrest (CDKN1A), DNA repair $(G A D D 45 A, G A D D 45 B)$ and ultimately apoptosis $(B A X)$ were identified as overexpressed, corroborating previous finding of TP53 induction as a marker of direct DNA damage (Yang and Duerksen-Hughes, 1998). Although TP53 mRNA was unchanged during washout, "classical" targets of the protein (i.e., MDM2, $C D K N 1 A$ and $B A X)$, were determined as the main targets of these FFLs. This is consistent with post-transcriptional regulation of p53 protein (e.g. increased protein half-life after genotoxic insult) (Kruse and $\mathrm{Gu}, 2009$ ). While the precise roles played by many of the identified TFs remain unclear, overexpression of CEBPA, KLF4, STAT1 as well as repression of $A R$ have also been previously reported as outcomes of p53-dependent mechanisms arising from genotoxic insult (Mantoni et al., 2006; Townsend et al., 2005; Yoon et al., 2003; Yoon and Smart, 2004). Furthermore, cessation of expression following removal of AFB1 may suggest an immediate response to sudden, extreme injury (Denissenko et al., 1998). Conversely, TF-coding genes MYC, HIF1A, CEBPB, known to control broader aspects of a cell's physiology (growth, metabolism, regeneration), not only prevailed during and after AFB1 exposure but also staged an intricate web of C1 FFLs.

From the larger number of C1 FFLs in networks after five days of continuous exposure, 25 persisted during washout, featuring
MYC and HIF1A as main conjoined regulators. Literature mining confirmed the collaborative aspect of these transcription factors (Dang, 2007; Dang et al., 2008; Doe et al., 2012; Lin et al., 2010), and since several target genes have been described as to their functional roles, henceforward we will focus on this particular interaction to exemplify our initial motivation. MYC is a potent oncogene that orchestrates the expression of $10-15 \%$ of cellular genes and microRNAs involved in proliferation, differentiation, cell cycle and apoptosis. HIF1a is a transcription factor that modulates genes related to energetic metabolism, being particularly active in hypoxic conditions (Dang et al., 2008). In a cooperative scenario, it was previously shown that when MYC is overexpressed a collaboration with HIF1a protein takes place, favoring lactate production over oxidative phosphorylation as energy source (aerobic glycolysis, also known as the Warburg effect) (Dang et al., 2008) even in normoxic conditions (Doe et al., 2012) (Fig. 4, A and B). In our study, three of five targets of joined MYC/HIF1A regulation are involved in energetic metabolism (NAMPT, ENO1 and NME1) (Fig. 4C). PMAIP1 (also known as NOXA), has been shown to lead to mitochondrial dysfunction during genotoxic stress (Seo et al., 2003) and the transferrin receptor (TFRC), an important mediator of iron uptake, further contributes to the Warburg effect and the proliferative potential of myc-enriched cells (Dang et al., 2008; O'Donnell et al., 2006). A series of MYC/HIF1A targets exclusively upregulated during washout suggests amplification - a consequence from feed-forward control - of aerobic glycolysis, including HK2 and ALDOA, pivotal enzymes for maintaining glycolytic flux. Interestingly, a recent publication has shown that $A L D O A$ is an important driver of glycolysis, which in turn increases HIF1A activity and cancer cell survival (Grandjean et al., 2016).

The Warburg effect, however, represents a causality dilemma. When it was initially proposed (more than 80 years ago), the author pointed towards enhanced glycolysis as a turning point which would eventually lead to selective advantage of a malignant
A.

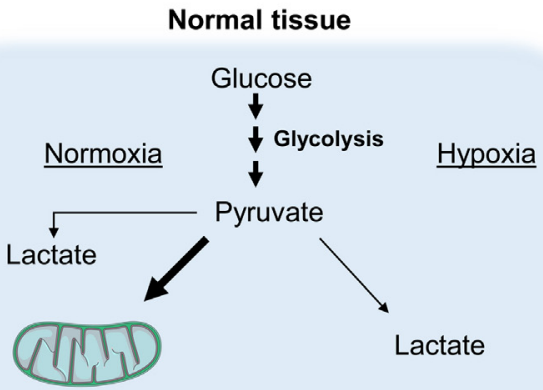

Oxidative phosphorylation Anaerobic glycolysis
B.

\section{Proliferative cells}

Tumor tissue

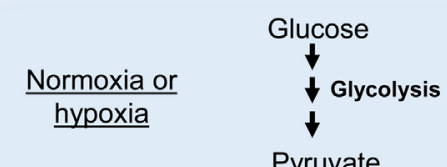

Pyruvate
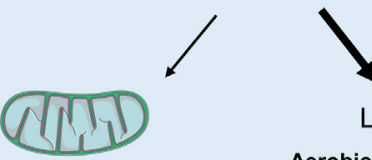

Lactate

Oxidative phosphorylation

Aerobic glycolysis (Warburg effect) Enhances proliferation phenotype

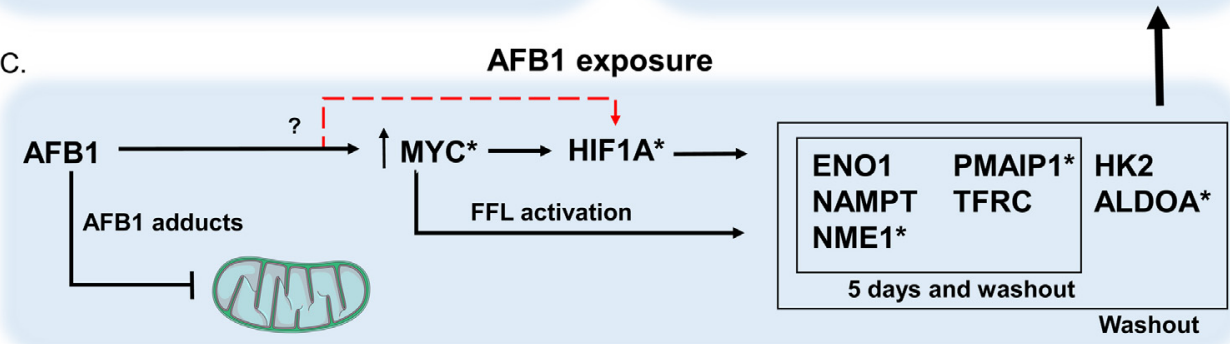

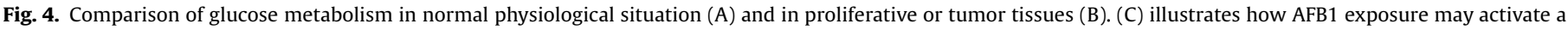

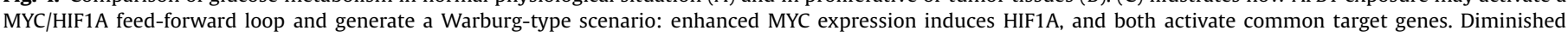

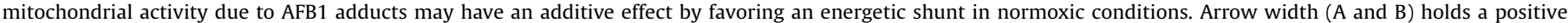

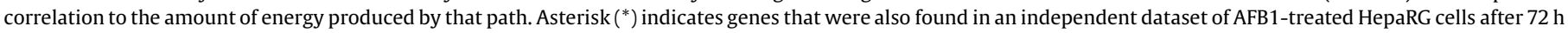
of single exposure (expression values are detailed in Supplementary data). 
phenotype (Warburg, 1930). Although evidence has shown that enhanced glycolysis predisposes cells to malignant transformation by aiding cell immortalization (Kim and Dang, 2006; Kondoh, 2008; Kondoh et al., 2005), it is now generally accepted that metabolic changes are intermediate steps (Hanahan and Weinberg, 2011), or even a resulting phenotype, of the current multi-stage model of oncogenesis. Nonetheless, even after a short exposure period, AFB1 datasets evidenced some of the proposed mechanisms culminating in the Warburg effect (Kroemer, 2006) including upregulation of glycolytic genes (NAMPT, ENO1, NME1), hypoxic switch (HIF1A overexpression) and mitochondrial dysfunction (represented by increased NOXA and supported by in vivo rodent studies showing preferential inhibition of mitochondrial activity in comparison to other organelles) (Niranjan et al., 1982).

Although these initial alterations may explain a pre-neoplastic state as long as there is exposure to the chemical, it does not explain how such changes can be maintained beyond exposure time. To this date, only E. coli has been used to model and validate kinetic models proposed for FFL behavior based on the relationships between the transcription factors and the promoter(s) of the target gene - "gates" - leading to enhanced expression (Kalir et al., 2005; Mangan et al., 2003). Supported by HIF1A and MYC integration (Dang et al., 2008) and the influence of MYC overexpression on modulation of HIF1A itself and its targets (Doe et al., 2012), we conclude that MYC/HIF1A fits the model proposed for a so-called "AND" gate. This type of gate requires the presence of both TFs at the promoter(s) - especially the driving node $(M Y C)$ - and constant, persistent input signaling (in this case, repeated exposure) to initiate the loop, which remains active as long as upstream signals are present. AFB1 not only has been shown to strongly induce MYC expression (at least 10-fold compared to controls) in livers of exposed rats, but also appears to do so without genetic alterations (i.e., gene amplification or rearrangement) - most likely associated to increased expression or stabilization of the mRNA (Larson et al., 1993). Furthermore, intracellular alterations (DNA damage, molecule adduction, oxidative stress and consecutive secondary messengers) may remain for a long period after ending the exposure. For instance, previous investigations have shown that AFB1-induced damage to mitochondria is fairly persistent: while nuclear transcription and nucleus-dependent translation processes are recovered after $12 \mathrm{~h}$ of exposure, these mitochondrial activities remain inhibited for at least $24 \mathrm{~h}$ (Niranjan et al., 1982). We hypothesize that such alterations, persistent after termination of exposure, may serve as input signals to FFLs - in this particular scenario contributing to prolongation and even exacerbation of the Warburg effect (Fig. 4C).

To validate these findings, we investigated independent datasets of AFB1-exposed liver cells for the presence of MYC/HIF1A FFL. We selected two datasets (GSE40117 and GSE28878), each containing transcriptomic measurements from single dose exposures and all generated by the same platform (for details refer to Supplementary data). For the first dataset, conducted with HepaRG cell line, we found that MYC, HIF1A, NME1, PMAIP1 and ALDOA were all significantly upregulated after $72 \mathrm{~h}$. In contrast, the remaining set, containing measurements from HepG2 cells, showed repression of MYC in all time points $(12,24,48$ and $72 \mathrm{~h})$, while all other genes apart from PMAIP1 (upregulated) and HK2 (downregulated) did not significantly change. This is remarkable since these results not only corroborate the proposed persistent "AND" loop (MYC should be present to induce HIF1A and target genes), but also indicates that these changes may be more critical to healthy hepatocytes, since HepaRG has been shown to superiorly mimic primary hepatocytes and liver in comparison to HepG2 (Jennen et al., 2010).
In summary, our analysis shows that feed-forward control, on the molecular (C1 FFLs) and even pathway level may be important players in toxicity and subsequent carcinogenesis: cell instability arising from frequent exposure and/or non-lethal but long-lasting alterations generate mediators that may act as input signals for (typically inactive) critical FFLs. Our results suggest that even a relatively short-lasting impulse by a chemical carcinogen may induce changes in pivotal cancer-related signaling pathways which are persistent after exposure has stopped. However, further experiments are needed to validate these findings and assess the relevance of unknown transcriptional interactions - especially from insufficiently investigated transcription factors - and the significance of the biological processes being regulated. The identification of stimul(i)us upstream to the FFLs, its persistence following termination of exposure may also aid risk assessment of chemicals by identifying common molecular events.

\section{Competing interests}

The authors declare that they have no competing interests.

\section{Author's contributions}

LR conducted the experimental work and pre-processed the data; TMS constructed the networks; TMS, TvdB, JK and DJ wrote the manuscript.

\section{Acknowledgements}

We thank the Brazilian National Council for Scientific and Technological Development (CNPq) through the program Science without Borders. The authors also want to thank S. van Breda for providing useful information regarding the experimental data used in this study.

\section{Appendix A. Supplementary data}

Supplementary data associated with this article can be found, in the online version, at http://dx.doi.org/10.1016/j.tox.2016.10.009.

\section{References}

Alon, U., 2007. Network motifs: theory and experimental approaches. Nat. Rev. Genet. 8, 450-461. doi:http://dx.doi.org/10.1038/nrg2102.

Bhattacharya, S., Zhang, Q., Carmichael, P.L., Boekelheide, K., Andersen, M.E., 2011 Toxicity testing in the 21 st century: defining new risk assessment approaches based on perturbation of intracellular toxicity pathways. PLoS One 6, e20887. doi:http://dx.doi.org/10.1371/journal.pone.0020887.

Blais, A., Dynlacht, B.D., 2005. Constructing transcriptional regulatory networks. Genes Dev. 19, 1499-1511. doi:http://dx.doi.org/10.1101/gad.1325605.

Dang, C.V., Kim, J., Gao, P., Yustein, J., 2008. The interplay between MYC and HIF in cancer. Nat. Rev. Cancer 8, 51-56. doi:http://dx.doi.org/10.1038/nrc2274.

Dang, C.V., 2007. The interplay between MYC and HIF in the Warburg effect. Ernst Schering Found. Symp. Proc. 35-53.

Denissenko, M.F., Koudriakova, T.B., Smith, L., O'Connor, T.R., Riggs, A.D., Pfeifer, G.P. 1998. The p53 codon 249 mutational hotspot in hepatocellular carcinoma is not related to selective formation or persistence of aflatoxin B1 adducts. Oncogene 17, 3007-3014. doi:http://dx.doi.org/10.1038/sj.onc.1202214.

Doe, M.R., Ascano, J.M., Kaur, M., Cole, M.D., 2012. Myc posttranscriptionally induces HIF1 protein and target gene expression in normal and cancer cells. Cancer Res. 72, 949-957. doi:http://dx.doi.org/10.1158/0008-5472.CAN-11-2371.

Gautier, L., Cope, L., Bolstad, B.M., Irizarry, R.A., 2004. affy-analysis of Affymetrix GeneChip data at the probe level. Bioinformatics 20, 307-315. doi:http://dx.doi. org/10.1093/bioinformatics/btg405.

Grandjean, G., de Jong, P.R., James, B.P., Koh, M.Y., Lemos, R., Kingston, J., Aleshin, A Bankston, L.A., Miller, C.P., Cho, E.J., Edupuganti, R., Devkota, A., Stancu, G. Liddington, R.C., Dalby, K.N., Powis, G., 2016. Definition of a novel feed-forward mechanism for glycolysis-HIF1 $\alpha$ signaling in hypoxic tumors highlights aldolase $\mathrm{A}$ as a therapeutic target. Cancer Res. 76, 4259-4269. doi:http://dx.doi. org/10.1158/0008-5472.CAN-16-0401. 
Hanahan, D., Weinberg, R.A., 2011. Hallmarks of cancer: the next generation. Cell 144, 646-674. doi:http://dx.doi.org/10.1016/j.cell.2011.02.013.

Jennen, D.G.J., Magkoufopoulou, C., Ketelslegers, H.B., van Herwijnen, M.H.M., Kleinjans, J.C.S., van Delft, J.H.M., 2010. Comparison of HepG2 and HepaRG by whole-genome gene expression analysis for the purpose of chemical hazard identification. Toxicol. Sci. 115, 66-79. doi:http://dx.doi.org/10.1093/toxsci/ kfq026.

Jennings, P., Limonciel, A., Felice, L., Leonard, M.O., 2013. An overview of transcriptional regulation in response to toxicological insult. Arch. Toxicol. 87, 49-72. doi:http://dx.doi.org/10.1007/s00204-012-0919-y.

Kalir, S., Mangan, S., Alon, U., 2005. A coherent feed-forward loop with a SUM input function prolongs flagella expression in Escherichia coli. Mol. Syst. Biol. 1, 2005.0006. doi:http://dx.doi.org/10.1038/msb4100010.

Kim, J., Dang, C.V., 2006. Cancer's molecular sweet tooth and the Warburg effect. Cancer Res. 66, 8927-8930. doi:http://dx.doi.org/10.1158/0008-5472.CAN-061501.

Kondoh, H., Lleonart, M.E., Gil, J., Wang, J., Degan, P., Peters, G., Martinez, D., Carnero, A., Beach, D., 2005. Glycolytic enzymes can modulate cellular life span. Cancer Res. 65, 177-185.

Kondoh, H., 2008. Cellular life span and the Warburg effect. Exp. Cell Res. 314, 1923 1928. doi:http://dx.doi.org/10.1016/j.yexcr.2008.03.007.

Kroemer, G., 2006. Mitochondria in cancer. Oncogene 25, 4630-4632. doi:http://dx. doi.org/10.1038/sj.onc.1209589.

Kruse, J.-P., Gu, W., 2009. Modes of p53 regulation. Cell 137, 609-622. doi:http://dx. doi.org/10.1016/j.cell.2009.04.050.

Larson, P.S., McMahon, G., Wogan, G.N., 1993. Modulation of c-myc gene expression in rat livers by aflatoxin B1 exposure and age. Fundam. Appl. Toxicol. 20, 316324.

Lin, C.-P., Liu, C.-R., Lee, C.-N., Chan, T.-S., Liu, H.E., 2010. Targeting c-Myc as a novel approach for hepatocellular carcinoma. World J. Hepatol. 2, 16-20. doi:http:// dx.doi.org/10.4254/wjh.v2.i1.16.

Mangan, S., Zaslaver, A., Alon, U., 2003. The coherent feedforward loop serves as a sign-sensitive delay element in transcription networks. J. Mol. Biol. 334, $197-$ 204. doi:http://dx.doi.org/10.1016/j.jmb.2003.09.049.

Mantoni, T.S., Reid, G., Garrett, M.D., 2006. Androgen receptor activity is inhibited in response to genotoxic agents in a p53-independent manner. Oncogene 25 3139-3149. doi:http://dx.doi.org/10.1038/sj.onc.1209347.

Merrick, B.A., Phadke, D.P., Auerbach, S.S., Mav, D., Stiegelmeyer, S.M., Shah, R.R. Tice, R.R., 2013. RNA-Seq profiling reveals novel hepatic gene expression pattern in aflatoxin B1 treated rats. PLoS One 8, e61768. doi:http://dx.doi.org/10.1371/ journal.pone.0061768.

Milo, R., Shen-Orr, S., Itzkovitz, S., Kashtan, N., Chklovskii, D., Alon, U., 2002. Network motifs: simple building blocks of complex networks. Science 298, 824-827. doi: http://dx.doi.org/10.1126/science.298.5594.824.

Nebert, D.W., Dalton, T.P., Okey, A.B., Gonzalez, F.J., 2004. Role of aryl hydrocarbon receptor-mediated induction of the CYP1 enzymes in environmental toxicity and cancer. J. Biol. Chem. 279, 23847-23850. doi:http://dx.doi.org/10.1074/jbc. R400004200.
Niranjan, B.G., Bhat, N.K., Avadhani, N.G., 1982. Preferential attack of mitochondrial DNA by aflatoxin B1 during hepatocarcinogenesis. Science 215, 73-75.

O’Donnell, K.A., Yu, D., Zeller, K.I., Kim, J.-W., Racke, F., Thomas-Tikhonenko, A., Dang C.V., 2006. Activation of transferrin receptor 1 by c-Myc enhances cellular proliferation and tumorigenesis. Mol. Cell. Biol. 26, 2373-2386. doi:http://dx. doi.org/10.1128/MCB.26.6.2373-2386.2006.

Palomero, T., Lim, W.K., Odom, D.T., Sulis, M.L., Real, P.J., Margolin, A., Barnes, K.C., O’Neil, J., Neuberg, D., Weng, A.P., Aster, J.C., Sigaux, F., Soulier, J., Look, A.T., Young, R.A., Califano, A., Ferrando, A.A., 2006. NOTCH1 directly regulates c-MYC and activates a feed-forward-loop transcriptional network promoting leukemic cell growth. Proc. Natl. Acad. Sci. U. S. A. 103, 18261-18266. doi:http://dx.doi. org/10.1073/pnas.0606108103.

Rieswijk, L., Claessen, S.M.H., Bekers, O., van Herwijnen, M., Theunissen, D.H.J., Jennen, D.G.J., de Kok, T.M.C.M., Kleinjans, J.C.S., van Breda, S.G.J., 2016. Aflatoxin B1 induces persistent epigenomic effects in primary human hepatocytes associated with hepatocellular carcinoma. Toxicology 350-352, 31-39. doi: http://dx.doi.org/10.1016/j.tox.2016.05.002.

Scardoni, G., Petterlini, M., Laudanna, C., 2009. Analyzing biological network parameters with CentiScaPe. Bioinformatics 25, 2857-2859. doi:http://dx.doi. org/10.1093/bioinformatics/btp517.

Seo, Y.-W., Shin, J.N., Ko, K.H., Cha, J.H., Park, J.Y., Lee, B.R., Yun, C.-W., Kim, Y.M., Seol, D., Kim, D., Yin, X.-M., Kim, T.-H., 2003. The molecular mechanism of Noxainduced mitochondrial dysfunction in p53-mediated cell death. J. Biol. Chem. 278, 48292-48299. doi:http://dx.doi.org/10.1074/jbc.M308785200.

Shmelkov, E., Tang, Z., Aifantis, I., Statnikov, A., 2011. Assessing quality and completeness of human transcriptional regulatory pathways on a genome-wide scale. Biol. Direct 6, 15. doi:http://dx.doi.org/10.1186/1745-6150-6-15.

Townsend, P.A., Cragg, M.S., Davidson, S.M., McCormick, J., Barry, S., Lawrence, K.M., Knight, R.A., Hubank, M., Chen, P.-L., Latchman, D.S., Stephanou, A., 2005. STAT1 facilitates the ATM activated checkpoint pathway following DNA damage. J. Cell Sci. 118, 1629-1639. doi:http://dx.doi.org/10.1242/jcs.01728.

Van Summeren, A., Renes, J., Bouwman, F.G., Noben, J.-P., van Delft, J.H.M., Kleinjans, J.C.S., Mariman, E.C.M., 2011. Proteomics investigations of drug-induced hepatotoxicity in HepG2 cells. Toxicol. Sci. 120, 109-122. doi:http://dx.doi.org/ $10.1093 /$ toxsci/kfq380.

Vaquerizas, J.M., Kummerfeld, S.K., Teichmann, S.A., Luscombe, N.M., 2009. A census of human transcription factors: function, expression and evolution. Nat. Rev. Genet. 10, 252-263. doi:http://dx.doi.org/10.1038/nrg2538.

Warburg, O., 1930. The Metabolism of Tumours. Constable, London.

Yang, J., Duerksen-Hughes, P., 1998. A new approach to identifying genotoxic carcinogens: p53 induction as an indicator of genotoxic damage. Carcinogenesis $19,1117-1125$

Yoon, K., Smart, R.C., 2004. C/EBPalpha is a DNA damage-inducible p53-regulated mediator of the G1 checkpoint in keratinocytes. Mol. Cell. Biol. 24, 1065010660. doi:http://dx.doi.org/10.1128/MCB.24.24.10650-10660.2004.

Yoon, H.S., Chen, X., Yang, V.W., 2003. Kruppel-like factor 4 mediates p53dependent G1/S cell cycle arrest in response to DNA damage. J. Biol. Chem. 278, 2101-2105. doi:http://dx.doi.org/10.1074/jbc.M211027200. 